\title{
Influence of Material with Medium and High Molecular Weight Replacing Polyethylene on Trawl Performance
}

\author{
Yongli LIU, lei WANG, Wenwen YU, Jiangao SHI, Ai zhong ZHOU, Lu min WANG \\ East China Sea Fisheries Research Institute, Chinese Academy of Fishery Sciences, Shanghai 200090, China
}

\begin{abstract}
Taking single-boat trawling fishing in West Africa as the research object and maintaining the breaking strength of the original netting gear as the standard, we used medium- and high-molecular-weight materials to replace common polyethylene material in producing the trawl model. Test results showed that, under the same test conditions, the resistance of medium- and high-molecular-weight material trawls decreased by $16.80 \%$ compared with that of most of the common polyethylene material trawls. The maximum difference in the height of the net opening between the two material trawls was approximately $2.3 \mathrm{~m}$. The energy consumption coefficient decreased by $23.65 \%$.
\end{abstract}

\section{Introduction}

Marine fishing-trawling boats in China account for 18\% of all marine fishing power-driven vessels, $25 \%$ of total power, and $48 \%$ of marine fishing yield [1] of the country. Thus, trawl fishing is significant in marine fishing in China. At present, energy saving and cost reduction are advocated. Meanwhile, the energy-saving and cost-reducing properties of netting gear are mainly evaluated based on overall resistance, height of net opening, energy consumption coefficient, power consumption [2-4], and other aspects. Currently, braided twines and other materials have been widely applied in trawl fishing abroad [5-9]. Medium- and high-molecular-weight polyethylene netting twines (new material) were used to replace common polyethylene netting twine (common material) to produce trawls that maintain the breaking strength of the original netting gear. The overall resistance, height of net opening, energy consumption coefficient, and power consumption of the two materials were compared to provide references for relevant studies on trawl fishing gear that promotes energy saving and cost reduction.

\section{Materials and methods}

\subsection{Test instruments and equipment}

The trawl model test was conducted in a fishing gear model test stilling basin with dimensions of $90 \mathrm{~m} \times 6 \mathrm{~m} \times$ $3 \mathrm{~m}$. The power of the trailer drive motor was $7.5 \mathrm{~kW} \times 4$. The trawling speed range was $0.1-4 \mathrm{~m} / \mathrm{s}$. The microprocessor speed of the governing system had a uniform velocity of $\mathrm{P} \leq 1 \%$. The tachymeter was a light electric tachometer with accuracy of $\pm 0.01 \%$. The measuring range of the force sensor was $100 \mathrm{~N}$ with nonlinear error of $0.4 \%$ F.S.C. The net height meter was an FE-6300 type net position depth sounder with range resolution of $30 \mathrm{~mm}$.

\subsection{Physical and model nets}

The physical prototype netting gear was produced by Weihai Haoyuntong Netting Gear Technology Co. Ltd. for single-boat trawling fishing in West Africa. The detailed parameters of the physical netting gear were as follows: The total length of the netting gear was $118 \mathrm{~m}$, the net opening perimeter was $280 \mathrm{~m}$, the headline length was $61.92 \mathrm{~m}$, the footline length was $80.25 \mathrm{~m}$, the number of net opening meshes was 56 with size of $5,000 \mathrm{~mm}$, the buoyancy force was $6,066 \mathrm{~N}$, the equipped sinking force was $9,330 \mathrm{~N}$, and the length of the empty line was $100 \mathrm{~m}$. With the criteria of maintaining the breaking strength of the original netting gear and having a "similar field" of application of the new material used to replace common material, the specification of the netting gear, size of the meshes, buoyancy force and equipped sinking force, rope accessories, and other parameters were all unchanged. According to the criteria for the prototype nets of the two types of netting twine materials in SC/T4014-1997 "Preparation of Trawl Model," two model nets were produced. The large-scale ratio of the two model nets was 20 and the small-scale ratio was 9 .

\subsection{Test methods}

The breaking and knot-breaking strengths of the samples of each specification were measured for the common polyethylene netting twines and the new material netting twines for replacement used in prototype netting gear. The model net was tested and processed according to the 
criteria and data in the SC/T4011-1995 Basin Test Methods of Trawl Model [10]. The model test simulated the empty line, with the end of the line used as the tow point and the test trawling speeds divided into seven grades with the range of $2.5-5.5 \mathrm{kn}$. Every $0.5 \mathrm{kn}$ was taken as a grade, and $0.35,0.40$, and 0.45 were taken as the three grades of the horizontal expansion of the model netting gear L/S (ratio of wingtip spacing and length of footline).

\subsection{Conversion relation between physical and model test data}

The mechanical proportional relation between physical and model net stresses was expressed as follows:

$\mathrm{F} 1=\mathrm{F} 2 \cdot \lambda 2 \cdot \lambda^{\prime}$. (1)

The conversion relation between physical and model heights of the net opening was expressed as follows:
$\mathrm{H} 1=\mathrm{H} 2 \cdot \lambda$.

In Formulas (1) and (2), $\lambda$ is the large scale ratio, $\lambda^{\prime}$ is the small-scale ratio, F1 is the physical net stress, F2 is the model net stress, H1 is the physical height of the net opening, and $\mathrm{H} 2$ is the model height of the net opening.

The calculation formula of the physical net energy consumption coefficient was expressed as

$$
\mathrm{Ce}=3.472^{\frac{F}{H \cdot L}}
$$

In Formula (3), Ce $[\mathrm{kW} \cdot \mathrm{h} \cdot(104 \mathrm{~m} 3)-1]$ is the energy consumption coefficient of the physical net under a certain set trawling speed, $\mathrm{F}(\mathrm{kN})$ is the calculated resistance of the physical net under the trawling speed, $\mathrm{H}$ (m) is the calculated height of the net opening of the physical net under the trawling speed, and L (m) is the wingtip horizontal expansion of the physical net.

The formula for calculating the value of the physical power consumption of the simulated part of the trawl under each set trawling speed was expressed as

$$
\mathrm{P}=\mathrm{FV} \text {. (4) }
$$

In Formula (4), P (kW) is the consumption power of the physical net under a certain set trawling speed, $\mathrm{F}(\mathrm{kN})$ is the calculated resistance of the physical net under the trawling speed, and $\mathrm{V}(\mathrm{m} / \mathrm{s})$ is the trawling speed of the physical net.

\section{Results and analysis}

\subsection{Resistance of netting gear}

Under the same test conditions, with the horizontal expansion L/S of $0.35,0.40$, and 0.45 , the resistance rates of the two netting gears are shown in Figure 1.

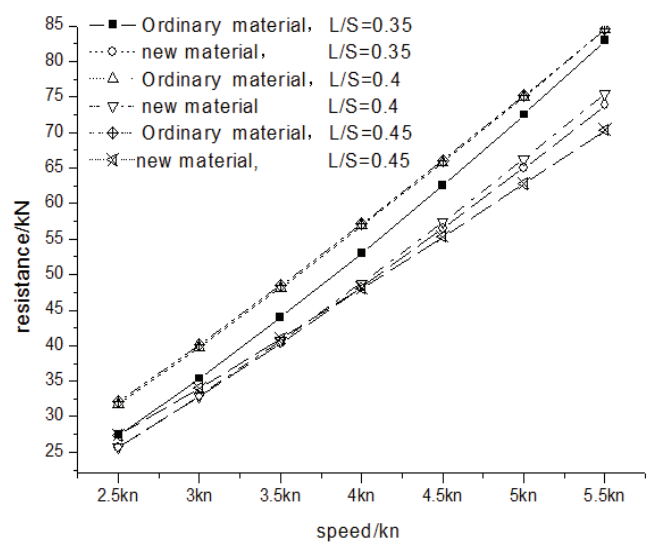

Fig. 1 Relationship curve of resistance \& speed

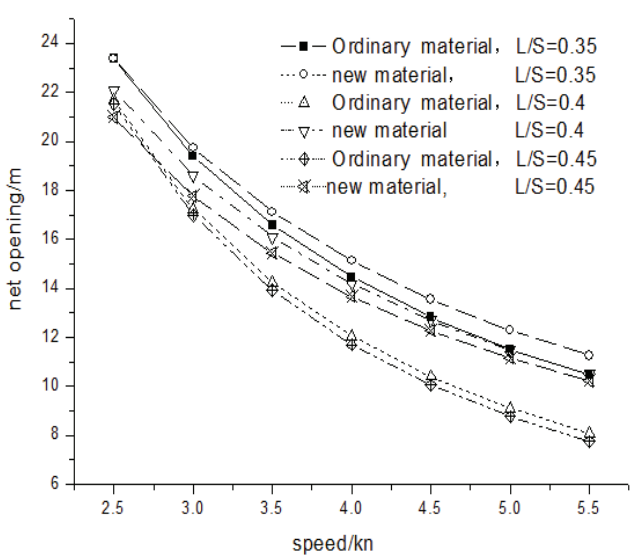

Fig. 2 Net opening under different trawling speeds

Figure 1 shows that the resistance of the netting gears increased continuously with the increase in trawling speed. The resistance of trawls of the common and new materials differed under various horizontal expansion conditions. In addition, given the same speed, the resistance was large when the horizontal expansion was large. Figure 1 also shows that, given the same speed and horizontal expansion, the resistance of trawls of the common material was larger than that of the new material. When $\mathrm{L} / \mathrm{S}=0.35$ and trawling speed was $2.5 \mathrm{kn}$, the resistance rates of the common and new materials were 35.23 and $33.09 \mathrm{kN}$, respectively, with a difference of $6.06 \%$. With the increase in L/S and trawling speed, the resistance of the common material trawls increased continuously and was greater than that of the new material trawls. When $\mathrm{L} / \mathrm{S}=0.45$ and the trawling speed was $5 \mathrm{kn}$, the resistance of the common material was $16.80 \%$ more than that of the new material.

\subsection{Height of net opening}

When the horizontal expansion L/S was $0.35,0.40$, and 0.45 , the results of the physical calculated height of the net opening of the two trawl models under different trawling speeds are presented in Figure 2.

Figure 2 shows that the height of the net opening of the two trawl models exhibited a declining trend with the increase in trawling speed. When the trawling speeds were the same, the height of the net opening of the two trawl models decreased with the increase in $\mathrm{L} / \mathrm{S}$. When 
L/S of the two trawl models was the same, the height of the net opening of the netting gear of common material was lower than that of the new material under the same trawling speed. When L/S was 0.45 and the trawling speed was $5 \mathrm{kn}$, the height of the net opening of the new material was $2.3 \mathrm{~m}$ higher than that of the common material and increased by $24 \%$ compared with that of the common material. Studies on trawl-fishing gear model test hold that the main factors influencing the height of the net opening are perimeter of strained net opening, buoyancy force and equipped sinking force, netting resistance, length of empty line, length of netting wing, and horizontal expansion of netting gear[11]. However, the two trawl models compared in this test were the same, except for the material, thereby indicating that the net opening vertical expansion of the new material netting gear was better than that of the common material netting gear.
The net is a mobile filter that filters the water body for fishing objects during sweeping in the sea and consumes energy during the dragging process. Therefore, based on the assumption that the fishing objects are evenly distributed in the water, a better method to describe fishing efficiency is used to express the values of the energy consumed by the trawl to filter a unit of water body [12]. The energy consumption coefficients of the two trawl models of different materials are shown in Table 1. The results indicate that under the same conditions, the energy consumption coefficient of the new material was lower than that of the common material. In other words, when filtering the same volume of water body, the energy consumed by the new material trawl is smaller than that of the common material trawl. When L/S was 0.45 and the trawling speed was $3.5 \mathrm{kn}$, the energy consumption of the new material was reduced by $23.65 \%$ compared with that of the common material.

\subsection{Energy consumption coefficient}

Tab 1 Energy consumption coefficient under different speeds

\begin{tabular}{ccccccc}
\hline Speed/(kn) & \multicolumn{5}{c}{$\begin{array}{c}\text { Energy consumption coefficient/Kw.h(104m3)-1 } \\
\text { Ordinary material trawl }\end{array}$} & \multicolumn{3}{c}{ New material trawl } \\
& $\mathbf{L} / \mathbf{S}=\mathbf{0 . 3 5}$ & $\mathbf{L} / \mathbf{S}=\mathbf{0 . 4}$ & $\mathbf{L} / \mathbf{S}=\mathbf{0 . 4 5}$ & $\mathbf{L} / \mathbf{S}=\mathbf{0 . 3 5}$ & $\mathbf{L} / \mathbf{S}=\mathbf{0 . 4}$ & $\mathbf{L} / \mathbf{S}=\mathbf{0 . 4 5}$ \\
\hline 2.5 & 0.144 & 0.158 & 0.143 & 0.135 & 0.125 & 0.125 \\
3.0 & 0.225 & 0.249 & 0.227 & 0.205 & 0.191 & 0.184 \\
3.5 & 0.326 & 0.365 & 0.334 & 0.290 & 0.272 & 0.255 \\
4.0 & 0.451 & 0.509 & 0.469 & 0.393 & 0.371 & 0.337 \\
4.5 & 0.601 & 0.683 & 0.631 & 0.513 & 0.487 & 0.433 \\
5.0 & 0.776 & 0.888 & 0.823 & 0.651 & 0.621 & 0.541 \\
5.5 & 0.977 & 1.126 & 1.047 & 0.807 & 0.775 & 0.661 \\
\hline
\end{tabular}

\subsection{Power consumption}

Table 2 shows the calculated values of physical net power consumption of the trawls of two materials under different trawling speeds when L/S was $0.35,0.40$, and 0.45 . Under the same test conditions, the power consumption of the new material trawl was smaller than that of the common material trawl. The analysis of the model test results showed that when a $440 \mathrm{~kW}$ fishing boat was trawling, approximately $12 \%$ of the total rated power can be normally applied to the simulated part of the netting gear in the model test [13-15]. Table 2 also shows that, while maintaining the horizontal expansion $\mathrm{L} / \mathrm{S}=0.45$ and the speed of $5 \mathrm{kn}$, given that the trawling time per day of the trawling fishing boat was $15 \mathrm{~h}$, and based on the assumption that the fuel oil consumption rate of the diesel engine was $196 \mathrm{~g} \cdot(\mathrm{kW} \cdot \mathrm{h})-1$, approximately $100 \mathrm{~L}$ fuel oil can be saved.

Tab 2 Relationship curve of power consumption \& speeds

\begin{tabular}{|c|c|c|c|c|c|c|}
\hline \multirow{3}{*}{ Speed/（kn） } & \multicolumn{6}{|c|}{ Power consumption coefficient $/ \mathrm{Kw}$} \\
\hline & \multicolumn{3}{|c|}{ Ordinary material trawl } & \multicolumn{3}{|c|}{ New material trawl } \\
\hline & $\mathbf{L} / \mathrm{S}=\mathbf{0 . 3 5}$ & $\mathrm{L} / \mathrm{S}=\mathbf{0 . 4}$ & $\mathrm{L} / \mathrm{S}=\mathbf{0 . 4 5}$ & $\mathrm{L} / \mathrm{S}=\mathbf{0 . 3 5}$ & $\mathrm{L} / \mathrm{S}=\mathbf{0 . 4}$ & $\mathrm{L} / \mathrm{S}=\mathbf{0 . 4 5}$ \\
\hline 2.5 & 35.23 & 40.80 & 41.25 & 33.09 & 33.00 & 35.20 \\
\hline 3.0 & 54.60 & 61.41 & 61.95 & 50.67 & 50.81 & 52.55 \\
\hline 3.5 & 79.12 & 86.75 & 87.36 & 72.63 & 73.19 & 73.73 \\
\hline 4.0 & 109.08 & 117.03 & 117.66 & 99.23 & 100.42 & 98.90 \\
\hline 4.5 & 144.80 & 152.40 & 153.00 & 130.68 & 132.72 & 128.11 \\
\hline 5.0 & 186.54 & 193.02 & 193.51 & 167.17 & 170.33 & 161.48 \\
\hline 5.5 & 234.62 & 239.00 & 239.34 & 208.87 & 213.45 & 199.14 \\
\hline
\end{tabular}

\section{Conclusion}

Based on energy saving and cost reduction as the permanent theme, the new material trawl was used to replace the common material trawl. Although the theoretical calculation of saved fuel oil volume cannot be used to precisely measure the saved fuel oil volume in practical production, the experimental results showed that the new material can reduce the netting gear resistance and improve the height of the net opening in netting gear application. In other words, the sweeping area in the sea increased and the resistance decreased, thereby reducing the fuel oil consumption and achieving energy saving and cost reduction to a certain extent. 


\section{Acknowledgements}

The research work was supported by the National Key Te chnology R\&D Program No. 2013BAD13B02 and Central Public-interest Scientific Institution Basal Research Fund, CAFS, No. 2017HY-ZD0605.

\section{References}

1. 2011China fishery statistics yearbook [M]. Beijing: China agricultural press, 2011.

2. Zhou A, Zhang Y, Yu Y g, et al. Experimental research on trawl performance of braided polyethylene netting twine replacing common polyethylene twisting [J] Marine fisheries, 2013, 35 (1), 98-101.

3. Zhou A, Zhang Y, Xu G, et al. Single ship towing four net-type double rig shrimp trawl model testing [J] Marine fisheries, 2014, 36(4), 364-371.

4. MATTK B, DAVID J S, RUSSELL B M. Effects of side taper on engineering and catching performances [J]. Fisheries Research, 2012, 12(134-136):73-81.

5. ANDREW S R, SIMON J. The capacity of benthos release panels to reduce the impacts of beam trawls on benthic communities[J]. Fisheries Research, 2005, $75(1-3): 73-85$.

6. HEIDI M, RUNE H G, ANNA O, et a1. Resistance of aquaculture net cage materials to biting by Atlantic Cod (Gadus morhua ) $[\mathrm{J}]$. Aquaculture Engineering, 2009, 40(3) :126-134.

7. MALIN H, ARNE F, SVEN G L, The pontoon trap: Description and function of a seal-safe trap-net $[\mathrm{J}]$. Fisheries Research, 2008, 93(3) :357-359.

8. GRAHAM K J. BROADHURST M K, MILLAR R $B$. Effects of codend circumference and twine diameter on selection in south. eastern Australian fish trawls $[\mathrm{J}]$. Fisheries Research, 2009, 95(2-3):341-349.

9. JOHN W V. Technological trends in capture fisheries. Ocean \& Coastal Management[J]. 2001, 44(9-10):635-651.

10. National fishery standardization technical committee, technical committee of fishery tools. SC/T4011-1995 towing model pond test method [s]. Beijing: China standard press, 1998:92-101.

11. Chen X, Xu B, Xiang Y, et al. An analysis of vertical expansion of bottom trawl network [c] //China fisheries research symposium. Suzhou: Su Zhou university press, 1997:163-170.

12. Wu Y, Yu Y, Li H, et al. A study of several issues in the trawl model test [c] // China fisheries research symposium proceedings. Suzhou: $\mathrm{Su}$ Zhou university press, 1997:27-36.

13. Cui J. On matching towing power and gear system for medium stern trawler[J]. Journal of Fisheries of China, 1993, 17(4) :289-296.

14. Friedman. Theory and design of fishing gear [M]. Hou H, Gao Q, translated. Beijing: china ocean press, 1988.

15. Ji X. Design and use of large mesh trawl fis hing gear[J]. Marine fisheries, 2000, 22(2):49—51. 